\title{
Poly-HEMA as a material for intraocular lens implantation: a preliminary report
}

\author{
R. B. S. PACKARD, A. GARNER, AND E. J. ARNOTT \\ From the Institute of Ophthalmology, London, and Charing Cross Hospital, London
}

SUMMARY A new soft material (poly-HEMA) has been implanted into a number of rabbit eyes in order to evaluate its use in lens implantation following cataract surgery. No reaction to the implant was seen on light microscopy of the sectioned enucleated eyes.

It is now a little over 30 years since Ridley ${ }^{1}$ started his pioneering work on the use of acrylic for replacing the lens removed at cataract surgery. Since that time many different types of lens have been manufactured with appendages of metal, nylon, prolene, etc., and these have been implanted into many hundreds of thousands of patients. The results have improved with advances in surgical technique and lens design, but few attempts have been made to try other substances ${ }^{2-6}$ for the optical part of the implant. Although polymethylmethacrylate is basically inert in the eye, it is a hard substance which requires some form of loop or iris stitch or contact by a foot or feet to the inside of the globe to maintain stability. It is this hardness which has led to a number of complications of intraocular lens implantation, namely, corneal decompensation due to loss of endothelial cells from lens touch whether at surgery or later, iris erosion leading to atrophy, secondary glaucoma, and intermittent hyphaema. These have all been widely reported.

With this in mind and remembering the criteria for an ideal implant material suggested by Seales, ${ }^{7}$ we looked for a new plastic to try. It needs to be (1) chemically inert; (2) not physically modified by contact with tissues; (3) acceptable to the body, with no inflammation or foreign body reaction; (4) noncarcinogenic; (5) nonallergenic; (6) capable of fabrication to a desired form; (7) capable of resisting mechanical strains; and (8) readily sterilisable. Polymethylmethacrylate fills many of these criteria, but ideally a material which more closely resembles the consistency of the natural lens should be sought.

Correspondence to Mr R. B. S. Packard, FRCS, Department of Ophthalmology, Charing Cross Hospital, Fulham Palace Road, London W6.
Table 1 Specifications of lens material

\begin{tabular}{lll}
\hline Material properties & & DIN \\
\hline Tensile strength $\left(\mathrm{kp} / \mathrm{cm}^{2}\right)$ & 57 & $53371 / 53455 / 53504$ \\
Density $\left(\mathrm{g} / \mathrm{cm}^{2}\right)$ & $1 \cdot 262$ & \\
Refractive index & $1.51 \pm 0 \cdot 1$ & \\
Water absorption (\%) & $42 \pm 2$ & \\
Transparency (\%) & $>96$ & \\
Oxygen transmission* & up to 6.1 & \\
\hline
\end{tabular}

*According to Fatt: $\frac{\mathrm{cm}^{2} \times \mathrm{ml} \mathrm{O}}{\mathrm{s} \times \mathrm{ml} \times \mathrm{Torr}} \times 10^{-11}$, (room temperature/average centre thickness $0.40 \mathrm{~mm}$ ).

The material that we chose is a poly-HEMA. It is a fully polymerised methacrylate derivative called Flexsol 43, which is soft in an aqueous medium. The specification is shown in Table 1. The other reason for this plastic is that it has been passed by the United States Food and Drug Administration for ocular use.

\section{Materials and methods}

It was decided to use rabbits as the experimental animal recipient for the poly-HEMA lenses, because, although not ideal in terms of anaesthesia and the behaviour of the eye under surgical conditions, they were cheap and readily available. Also the effects of the material as a foreign body within the eye should be able to be demonstrated histologically with no great difficulty.

Two albino, 3 lop-eared, and 6 Dutch rabbits were used, the last type being most satisfactory to anaesthetise and also in the reaction of the eye to surgical injury. All the rabbits were anaesthetised with Sagatal (barbiturate) intravenously and $2 \%$ amethocaine drops to the eye.

Extracapsular lens removals were carried out on the right eye in each case. Firstly a careful "can 


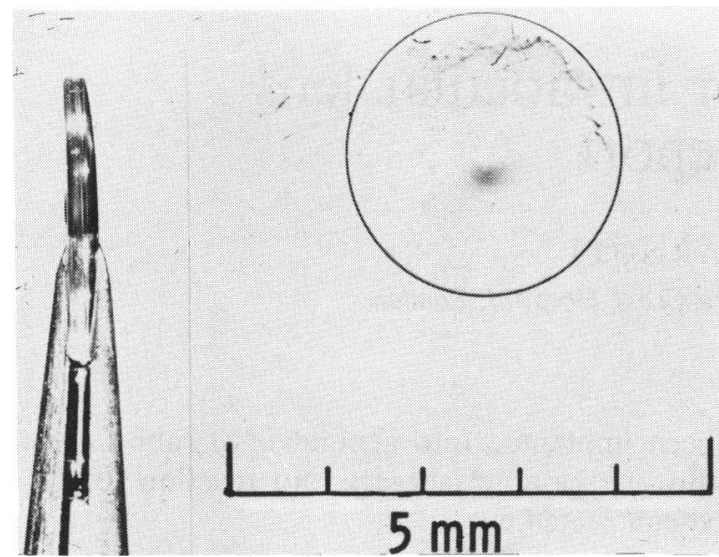

Fig. 1 Close-up of poly-HEMA lens.

opener capsulotomy' was performed, the lens nucleus expressed, and the residual cortex removed with a Cavitron-Kelman irrigation/aspiration apparatus. Finally the posterior capsule was polished, the lens inserted into the eye, and the wound closed with a continuous nylon suture. The lens measured approximately $3 \mathrm{~mm}$ in diameter and had a power of +15 doptres in aqueous. Of the 11 rabbits operated upon, 1 had no lens as a control, 2 had lenses into the anterior chamber, and 8 into the posterior. No postoperative medication of any kind was used.

The animals were observed clinically for a period of 3 months, because it has been shown ${ }^{8}$ that by this stage the healing process is complete within the eye. Thus for the purposes of this preliminary study it was decided to kill the rabbits at this stage and remove the operated eye for histology. This was carried out by light microscopy and the sections were stained with haematoxylin and eosin. The lens, which in a number of cases fragmented on sectioning, was homogeneously eosinophilic.

\section{Results}

The enucleated specimens were all examined histologically. They all showed a reaction to the surgical trauma and there was no difference between the control eye and other eyes in this respect. In all cases where a lens was implanted no reaction in the adjacent tissues, whether of a direct toxic or indirect immunological nature, was seen. These findings are detailed below and summarised in Table 2 .

LENS ALONE

An unimplanted lens embedded directly in paraffinwax was easily sectioned and was homogeneously

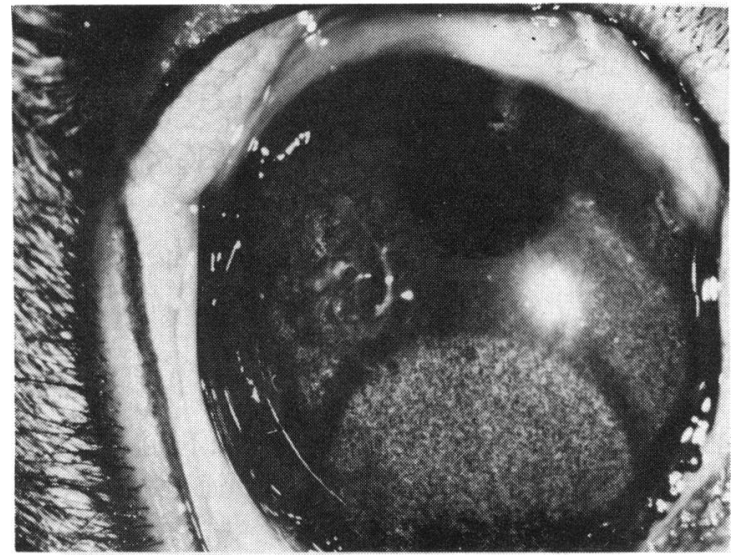

Fig. 2 Poly-HEMA lens in anterior chamber.

eosinophilic, while embedding in celloidin gave a much less satisfactory result, the lens tearing and fragmenting to a marked degree.

\section{LENSES IN RABBITS' EYES}

Rabbit 915. The cornea showed a little leucocytic infiltration of the superficial stroma together with some vascularisation at the periphery. A giant-cell reaction to retained suture material was also seen. There was persistence of lens tissue within a folded capsule. Some fragmented poly-HEMA was seen in the anterior chamber. There was no sign of intraocular inflammation.

Rabbit 854 . There was an inflammatory response to suture material in the peripheral cornea and at the limbus but no sign of inflammation within the eye. The lens was reduced in size, and in the centre of residual lens fibres there was fragmented polyHEMA material which seemed to have been inert in so far as there was no evidence of degenerative change in the adjacent lens tissue.

Rabbit 1052. The cornea was intact, and within the

Table 2 Summary of histological findings

\begin{tabular}{|c|c|c|c|c|}
\hline $\begin{array}{l}\text { Rabbit } \\
\text { no. }\end{array}$ & $\begin{array}{l}\text { Poly-HEMA } \\
\text { implant in } \\
\text { lens }\end{array}$ & $\begin{array}{l}\text { Poly-HEMA } \\
\text { implant in } \\
\text { anterior chamber }\end{array}$ & Uveitis & $\begin{array}{l}\text { Corneal } \\
\text { scarring } \\
\text { etc. }\end{array}$ \\
\hline 692 & - & - & - & + \\
\hline 717 & - & - & - & + \\
\hline 853 & - & - & - & + \\
\hline 854 & + & - & - & + \\
\hline 895 & - & - & - & + \\
\hline 915 & - & + & - & + \\
\hline 987 & - & + & - & + \\
\hline 1052 & + & - & - & - \\
\hline 1092 & - & - & - & + \\
\hline 1093 & - & - & - & + \\
\hline 2137 & - & - & - & + \\
\hline
\end{tabular}


residual lens tissue there was a poly-HEMA implant which appeared not to have engendered any local reaction. There was, however, very little subcapsular fibrosis anteriorly.

Rabbit 987. The cornea showed vascularisation and leucocytic infiltration of its anterior lamellae and some subepithelial fibrosis. On one side there was also a thick plaque of retrocorneal fibrous tissue. Residual lens material was seen within a slightly folded capsule. Poly-HEMA material was present in the anterior chamber in a fragmented state.

Rabbit 692. Vascularisation, leucocytic infiltration (slight) and scarring of the superficial cornea were present. Residual lens tissue within the incised capsule was cataractous, and fibrous synechiae between the anterior surface of the residual lens and iris margin were present also. Lens tissue was incarcerated in the pupillary margin of the iris. There was no sign of prosthetic lens material.

Rabbit 717 (control). There was an inflammatory response to retained suture material at the limbus. Residual cataractous lens material in a ring form was adherent to the ciliary processes, and there had been a peripheral iridectomy.

Rabbit 853. There was widespread vascularisation of the superficial corneal stroma, and on one side there was peripheral anterior synechia with endothelialisation and the formation of a Descemet's membrane crossing the angle and extending on to the iris. The lens showed evidence of capsular incision with removal of lens tissue, residual lens fibres were subject to vacuolation, and anteriorly there was a little subcapsular fibrosis. There was no evidence of intraocular inflammation. No prosthetic material was seen in the sections.

Rabbit 895 . The cornea was vascularised towards the periphery, and at one place, where Descemet's membrane had been divided, there was retrocorneal fibrosis. The lens capsule had been incised, and remnants of the lens were enclosed within a folded capsule associated with anterior subcapsular fibrosis. There was no sign of inflammation within the eye. Prosthetic material was not seen.

Rabbit 2137. There was vascularisation of the superficial cornea associated with some scarring in the region of the limbal incision. Some cataractous remnants of the lens were present within a folded capsule. There was no uveitis. Prosthetic material was not seen.

Rabbit 1093. Towards the limbus there was an inflammatory reaction to retained suture material, but otherwise the cornea was normal. A ring cataract was present within the incised lens capsule, but there was no intraocular inflammation. Prosthetic material was not seen.
Rabbit 1093. The cornea showed some superficial scarring and vascularisation towards the periphery, and there was a ring cataract. Intraocular inflammation was not seen, and there was no sign of prosethetic material.

Since a poly-HEMA implant was inserted in each case except one, it can only be assumed it was dislodged during processing of the globes. The poly-HEMA did not appear to provoke any reaction in the adjacent tissues, whether of a direct toxic or indirect immunological nature. Corneal changes were attributable to surgical considerations rather than the nature of the implant.

\section{Discussion}

It would seem from this preliminary study that in the short term at least the material used here produces no demonstrable tissue reaction. Whether over a longer period toxic substances might leach out of the lens is not known. Nor is it known whether the lens will itself be biodegraded within the eye. This study having shown that poly-HEMA may possibly be suitable for lens implanting in terms of tissue reaction, further work is now required to test the optical properties of the lens and its ideal form. The original idea had been to produce a lens which could be rolled up and placed in the eye following a Kelman phacoemulsification cataract extraction. Further developments are taking place along these lines.

As can be seen this study has satisfied all of Seales's criteria except its carcinogenic nature, which would require a much longer follow-up period for assessment.

\section{References}

1 Ridley H. Intraocular acrylic lenses. Trans Ophthalmol Soc UK 1951; 71 : 617-21.

2 Ruedemann AD. Silicone intraocular lenses in rabbits. Trans Am Ophthalmol Soc 1977; 75: 436-55.

3 Janevicius R, Peyman GA. Iris tissue reaction to intraocular materials: feasability for intraocular lens fixation. Ophthalmic Surg 1977; 8: 44-7.

4 Strampelli B. Anterior chamber lenses. Arch Ophthalmol 1961 ; 66: 12-7.

5 Binkhorst RD, Weinstein GW, Troutman RC. Weightless iseikonic intraocular lens. Am J Ophthalmol 1964; 58: 73-8.

6 Barasch K, Poler S. Glass intraocular lens. Am J Ophthalmol 1979; 88: 556-9.

7 Seales J. Discussion on metals and synthetic materials in relation to soft tissues; tissue reaction to synthetic materials. Proc $R$ Soc Med 1953; 46: 647-50.

8 Puchkov SG, Egorova EV, Grigorants TN. Function and morphological parameters in aphakia in rabbits. Vestn Oftalmol 1976; 93: 29-33. 